\title{
Toma de decisiones públicas desde las perspectivas del proceso tecnocrático y la participación ciudadana: caso venezolano
}

\author{
Hernández de Velazco, Judith Josefina*
}

\section{Resumen}

La gestión pública involucra la planificación y toma de decisiones con el objeto de satisfacer necesidades de la sociedad. Las decisiones pasan por un proceso específico dependiendo del paradigma administrativo que se practique; el caso venezolano se ha caracterizado por la adecuación de modelos empresariales al contexto público, desde donde se ha importado el proceso tecnocrático con sus respectivos dispositivos de acción. Por otra parte, se han definido con la constitución de 1999 nuevos esquemas para la gestión pública que incluye la participación de los ciudadanos en la misma. El objetivo de este trabajo, es evidenciar las divergencias que existen para el proceso de toma de decisiones municipales desde las perspectivas del fenómeno tecnocrático y de la participación ciudadana. La metodología consiste en investigación bibliográfica, y normativa; registro de la información; y síntesis analítica y crítica de la información recopilada. Análisis desde donde se concluye un sometimiento racional económico de la gestión pública que restringe la participación de los ciudadanos, entre otras cosas, por lo encontrado de ambas posiciones en cuanto a sus fines y objetivos. En consecuencia, se deben buscar mecanismos de eficacia social para una administración pública concertada, solidaria y mancomunada, donde se incluya a los ciudadanos con el soporte de los gobiernos municipales.

Palabras clave: Gestión pública, toma de decisiones, proceso tecnocrático, participación ciudadana, municipio.

Recibido: 21-06-06. Aceptado: 21-06-07

Lic. Ciencias Políticas y Administrativas. Diplomada en Ciudadanía, Control Democrático de la Gestión Pública y Participación Ciudadana. Master en Administración de Empresas. DocenteInvestigadora UNERMB. Candidata al Doctorado de Ciencias Sociales. Mención Gerencia. 


\title{
Public Decision Making from the Perspective of the Technocratic Process and Citizen Participation: the Case of Venezuela
}

\begin{abstract}
Public management involves planning and decision making with the objective of satisfying society's needs. Decisions pass through a specific process depending on the administrative paradigm in practice; the case of Venezuela has been characterized by the adjustment of business models to the public context, from whence the technocratic process with its respective action devices have been imported. On the other hand, under the 1999 Constitution, new public management strategies have been defined that include citizen participation. The objective of this study was to demonstrate the divergences that exist for the municipal decision-making process from the perspectives of technocratic phenomenon and citizen participation. Methodology consisted of bibliographic research and research about regulations; registry of the information; and analytical and critical synthesis of the compiled information. Analysis led to the conclusions that public management is subject to a rational economic domination that restricts citizen participation, among other things, according to what was found in both positions in terms of their aims and objectives. Consequently, mechanisms for social effectiveness should be sought to create public administration that is mutually agreed on, supportive and united, in which citizens are included with the support of municipal governments.
\end{abstract}

Key words: Public management, decision making, technocratic process, citizen participation, municipality.

\section{Introducción}

La gestión pública, como proceso, ejecuta decisiones, administra y distribuye recursos como respuesta a las demandas colectivas y se supone su ejercicio debe acompañarse de un compromiso y sensibilidad social. Sus elementos de acción, entre otros, implican, poder formular y aplicar políticas sociales coherentes con las realidades del contexto; definir objetivos a mediano y largo plazo para articularse con programas de amplio alcance y operar con diversos actores involucrados en el quehacer público.

Entre estos actores se incluye al ciudadano común, que debe involucrarse enérgicamente en las actividades públicas, pero siempre y cuando sea reconoci- do con la plenitud de sus derechos y deberes, al incluirse en la definición y resolución de los problemas que son de su interés, individual y comunitario.

Lógicamente el modelo actual de administración pública no coincide con las características de esa gerencia pública antes descrita: social, coherente, articulada e incluyente; por el contrario percibimos divergencias que son las que pretendemos evidenciar en las páginas siguientes.

En la gestión pública venezolana se han aplicado criterios de racionalidad económica, a manera de profundizar el papel del Estado en el proceso de acumulación, por lo cual sus decisiones han sido orientadas con criterios de productividad y crecimiento económico. Tales criterios 
han sido asimilados de los conceptos de la gerencia empresarial, donde la gestión en su ejecución y resultados es evaluada cuantitativamente según ciertos parámetros e indicadores tales como eficiencia, efectividad y otros.

Desde el punto de vista institucional, para alcanzar los objetivos de la racionalidad económica, la administración pública se ha caracterizado por tener como parámetros: un modelo burocrático de su organización, un funcionariado técnico especializado, una estructura jerarquizada y autoritaria, una estricta delimitación de deberes, derechos y responsabilidades y un proceso de toma de decisiones centralizado.

De allí se deriva la caracterización del recurso humano que interviene en la administración pública: un cuerpo técni$\mathrm{co}$, profesional, especializado, experto, definido como tecnócrata con poder en la toma de decisiones, formado para y por la racionalidad económica y productiva.

De una u otra forma los criterios con los cuales se ejerce la administración pública determinan positiva o negativamente las posibilidades de participación de los ciudadanos en su gestión. Hablamos de participación en la medida en que los ciudadanos tengan capacidad de decidir, controlar, ejecutar y evaluar los procesos de la gestión, de lo contrario serian ciudadanos pasivos, simples receptores de las decisiones y políticas diseñadas por otros; sobre todo cuando se considera que para lo público su piso de justificación son las decisiones sociales, y por ende, más que considerar la relación costo-beneficio debe prevalecer el criterio de una amplia cobertura con el propósito de satisfacer las exigencias del mayor nu- mero de ciudadanos posible, es decir la eficacia más el servicio social.

Todo lo señalado anteriormente, entraña también tomar en cuenta que en la actividad empresarial se suministran bienes y servicios de cualquier orden, pero para la actividad pública son los bienes o servicios públicos tales como: agua, electricidad, seguridad y otros, cuyas características de no excluyente ni de exclusividad ni discrecionalidad, para proporcionarlo requieren de un tratamiento estratégico, el cual no puede estar basado únicamente en criterios de productividad.

En concordancia con lo anterior, el objetivo en esta reflexión es discutir sobre la toma de decisiones públicas en Venezuela y cómo se produce la misma según la visión tecnocrática o según la visión de la participación ciudadana.

Por lo cual, nuestra hipótesis es que la participación ciudadana y el proceso tecnocrático presentan diferencias en su aplicación para la gestión pública, concretamente en el proceso de toma de decisiones. Lo cual será abordado desde la realidad de la administración pública tecnocrática, analizada en bibliografías e investigaciones del área y desde la perspectiva teórica de la intervención del ciudadano en los asuntos públicos, contenida en la normativa constitucional venezolana específicamente relacionada con el contexto municipal.

Es necesario aclarar que en esta reflexión los conceptos utilizados como los de administración, gestión y gerencia son manejados indistintamente como sinónimos, a objeto de generar el análisis bibliográfico sin ampliar la explicación conceptual y etimológica para cada autor. 
También se reconoce como proceso de administración lo aceptado por la generalidad de las fuentes autorizadas, es decir las diferentes etapas: planeación y toma de decisión, organización, dirección, evaluación y control, utilizando para nuestro desarrollo concretamente la de toma de decisiones.

La aplicación de tales conceptos se concentra en la estrategia de como han sido desarrollados en la teoría empresarial y como han sido implementados en el ámbito público, pero con las características específicas de cada perspectiva; desde la participación ciudadana determinada por la forma ideal de los compromisos sociales y desde la tecnocracia determinada por la racionalidad económica capitalista.

\section{Desarrollo}

La sociedad como espacio de interacción de los individuos ha permitido históricamente la creación de instituciones para regular sus relaciones y establecer varios mecanismos en la organización de la misma; así se definen: los límites en cuanto a los derechos y deberes en general; el reconocimiento de la propiedad privada; el establecimiento de controles jurídicos y administrativos y la sumisión de esa sociedad a un ente centralizador reconocido como el Estado, el cual es necesario para garantizar la consecución de fines y objetivos así como la definición de los procesos que concretan su acción.

\subsection{Consideraciones del Estado}

El Estado expresa en sí la organización e instrumentación de una unidad reguladora de las relaciones de los individuos dentro de un espacio determinado. Dentro de este espacio los individuos no sólo comparten una cultura, historia y tradiciones, sino también, su caracterización política, es decir; cómo se ha utilizado el poder, quiénes y para quiénes lo han ejercido, y cuáles han sido sus alcances y consecuencias para gobernados y gobernantes.

Dicho Estado se ha organizado en la cultura occidental estrechamente vinculado al desarrollo capitalista en sus funciones de legitimación y acumulación de capital. La primera se refiere a las relaciones de poder en su dimensión estrictamente política y la segunda, se identifica con su carácter operativo, ejecutorio, expresado a través de la administración o gestión pública que administra y asigna recursos. De acuerdo con Gamboa y Suárez (1997:63),

es necesario considerar que con la instauración del modo de producción capitalista se produce la separación -al menos aparente- del poder político y del poder económico. El primero queda en manos del gobierno, que comienza a figurar como representante de los intereses comunes, aunque continué siendo defensor de los intereses de la clase económicamente dominante.

Esta ha sido una constante a pesar de las diferentes transformaciones del Estado y sus respectivas adecuaciones al entorno socio-económico. Caso concreto se puede apreciar con el Estado de Bienestar, con el cual se fortalecen los asuntos privados en el espacio público. Por consiguiente, asume como competencia estatal: la lucha de los derechos sociales, la regulación del trabajo y los 
derechos de menores; lo que Coriat (1982) define, como la entrada del Estado en una gestión enteramente nueva de las fuerzas de trabajo y de la acumulación de capital, asegurando para sí un nuevo terreno de legitimación y una doble función: gestión de los grandes equilibrios del proceso de acumulación, y de la relación de explotación en la producción en masa, de esa forma acopla la gestión de la fuerza de trabajo obrera a la acumulación de capital.

El Estado se concibe en su macroespacio como órgano decisorio superior de la nación con capacidad de imposición de sus decisiones a la sociedad, ahora si en esa toma de decisiones satisface o desatiende demandas y necesidades del colectivo (como en efecto desatiende por la valoración de intereses dominantes) puede favorecer o afectar su legitimidad y representatividad. De cualquier forma ambas condiciones repercuten en el espectro de las relaciones Estado-Sociedad, relaciones que reflejan las consecuencias de las acciones del Estado dentro de su contexto social.

El Estado debería actuar para el beneficio del interés de la ciudadanía cuando se auto-define representante del colectivo, pero ocurre que los verdaderos intereses del Estado (los cuales privilegian a las clases dominantes) pueden entrar en conflicto con los intereses sociales. Producto de esta realidad de adecuación de los fines del Estado con las necesidades sociales, se produce un desgaste en su funcionamiento, arrojando como resultado un profundo descontento de la sociedad en cuanto a su gestión, por lo cual se habla de una crisis del Estado.
En el análisis de tal crisis se han considerado diversas causas, como: las sucesivas depresiones económicas, las fracasadas reformas del Estado y de la administración pública y en general la incapacidad de los gobiernos para dar respuestas a las demandas sociales cada día más variadas y numerosas, con un capacidad de respuesta dependiente de un sistema sobrecargado y con deficientes recursos.

Como expresa Pastor (1999), la legitimidad de un orden político debe circunscribirse a ejercer el poder y el gobierno con el consentimiento de los gobernados, la estructura instrumental del orden político es la representación y la participación con sus respectivos intermediarios como los partidos políticos y/o grupos sociales, para expresar la pluralidad de intereses sociales en la toma de decisiones. Sin embargo la realidad ha evidenciado una crisis de legitimidad, venida desde el sistema representativo y de la ineficiencia del sistema y de los diversos intermediarios.

También se ha tratado de explicar dicha crisis desde dos concepciones estrictamente opuestas pero coincidentes en este asunto; a saber, la concepción neomarxista y la liberal. Vallespín (2000) sintetiza ambas corrientes cuando plantea que la crisis del estado y de su gobernabilidad surge con la existencia de una distorsión sistémica interna en el ejercicio de la acción del gobierno y es dado porque el Estado se obliga a una ampliación de sus pretensiones sociales pero dispone cada vez de menos recursos, haciendo su legitimidad cada vez más débil. Por lo cual, se produce un desfase entre lo que se solicita al Estado y lo que está en 
condiciones de dar. Lógicamente el efecto en cascada del desfase involucra a todos los elementos del Estado, incluida su administración pública.

Además, que al sobredimensionado circuito de exigencias al que se expone en la actualidad el sistema político, se le añade por parte de los ciudadanos un cambio de visión en las respuestas a sus requerimientos, las cuales deben ser satisfecha cuantitativamente y cualitativamente para alcanzar una mejor calidad de vida.

\subsection{Gestión pública}

El Estado se expresa a través de la administración pública, como ya se ha mencionado, y las capacidades de la gestión se orientan según los objetivos definidos por la acción política, involucrando las decisiones respectivas; es decir, los objetivos definen la acción de la gestión pública desde el uso, cantidad y destino de los recursos hasta la intervención de diversos actores tanto públicos como privados. "A través de ella la dimensión política o sustantiva del Estado se explicita y desenvuelve en el funcionamiento cotidiano de las agencias públicas (gobierno central, tribunales, etc.) y en sus múltiples relaciones con la sociedad...la relación entre la gestión pública, la estructura socioeconómica y las orientaciones políticas del Estado siempre es estrecha" (Vilas, 2001:177-178). En consecuencia, la administración pública es la expresión organizada del Estado y en ella se ha manifestado la estructura burocrática a la que le ha correspondido funciones de aparato represivo, de control social y político (Kaplan, 1997), con lo que termina siendo un ejecutor de los intereses de la elite del poder capitalista.

Desde la misma instauración de la gran industria y sus formas capitalistas la asociación entre el Estado y la Empresa ha sido muy permeable, hasta el punto de que muchos aspectos para ser transformados en la administración pública se han intentado adaptar desde los conceptos de la gerencia empresarial, esquemas que han sido concebidos para resolver los problemas de producción del sector privado, y que al ser aplicados al sector público resultan una inconsistencia teórica y epistemológica (Córdova, 2000). Esto se evidencia cuando el sector público asimila los conceptos aplicados en la empresa con los mismos criterios racionales, obviando que: 1) los objetivos tienen alcances diferentes, 2) la cobertura de sus pretensiones en el caso de la gestión pública implica asumir costos muy altos pero justos y equitativos, 3) y la rendición de cuentas del sector gubernamental es de carácter publico, entro otros aspectos.

En ese orden de ideas, Vilas (2001) señala que la política fiscal de un Estado más barato coloca el énfasis en enfoques instrumentales que reducen los problemas del Estado a cuestiones operativas, es decir minimiza la trascendencia de las prioridades sociales al ser consideradas como asuntos operativos o procedimientos. Se sacrifica el interés social, porque lo técnico es abordado por expertos y no por los propios interesados.

La frontera entre las decisiones técnicas y decisiones políticas es absoluta, pero la presentación de las cuestiones políticas como si se tratara de asuntos técnicos usualmente restringe la discu- 
sión sobre la política y sus objetivos a ámbitos reducidos...mientras que la explicitación de las dimensiones políticas abre el debate al conjunto de la ciudadanía interesada o afectada por las decisiones que vayan a ser adoptadas (Vilas, 2001:175).

\subsection{Gestión pública municipal}

Lo planteado anteriormente es una realidad en América Latina y muy particularmente de Venezuela. La administración pública se caracteriza por sus funciones ideológicas y de represión, por su forma en la toma de decisiones central o descentralizada; por el tipo de administración sea nacional, regional o municipal, y su operatividad apegada a un modelo o paradigma de tipo burocrático.

Entendiendo la burocracia como sistema organizado bajo relaciones de suprasubordinación definidas desde el concepto de dominación y como función de aparato represivo, para lo cual se estructuran diferentes niveles jerárquicos constituidos por unidades especializadas dirigidas por técnicos. En consecuencia, las instituciones públicas venezolanas, incluidas las alcaldías se han manejado con modelos administrativos tradicionales, cuyos rasgos burocráticos determinan la gestión de las mismas, caracterizándose por: una estructura jerárquica autoritaria, delimitación de deberes, derechos y responsabilidades, asignación de funciones en virtud de la capacidad técnica demostrada, profesionalización de la gestión, y racionalidad técnica y de eficiencia (Broitman, 2004).

Al ponderar el modelo administrativo público surgen, varias limitaciones en su aplicación a la gestión social, señalándose su carácter discrecional que atenta contra la equidad; la impersonalización de la gestión contraria a la gestión solidaria; su estructura piramidal y autoritaria dificulta el manejo justo, oportuno e igualitario de las actividades en su seno; y la profesionalización (técnicos-especialistas) favorece las decisiones justificadas desde la racionalidad económica.

\subsection{Proceso tecnocrático}

La revolución industrial es un proceso de renovación técnica con profundas implicaciones sociales, filosóficas, económicas y políticas. En dicho proceso, el conocimiento científico se supedita al orden establecido y la justificación racional es influenciada por el pensamiento burgués de producción, determinando las condiciones materiales y mentales que el capital implica. La racionalidad instrumental productiva impone la realidad y el deber ser dentro de la sociedad, es decir desde la mentalidad capitalista de donde se desarrollan los sistemas de producción y la administración en la gran empresa.

De la vinculación de la ciencia con la técnica surge el proceso conocido como Revolución Científico-Técnica (RCT) el cual determinó la concentración del capital industrial para asimilar los avances tecnológicos y sus aplicaciones orientando las actividades de la gran empresa. De acuerdo con Ochoa (1995:15) “ la expansión de la gran empresa tiene lugar en la segunda mitad del siglo pasado y es consecuencia de la fusión de grandes capitales para incorporar el desarrollo científico-técnico en la producción y 
crear condiciones monopólicas, todo ello buscando acelerar el proceso de acumulación de capital".

En términos generales, la racionalidad científica se concentra en mantener los fines de rentabilidad del capital y para ello hace uso del criterio de productividad, de eficiencia como connotación técnica que oculta los fines reales tanto ideológicos, políticos y económicos (Ochoa, 1995). Desde esa óptica, se han fundamentado diversas escuelas del pensamiento administrativo surgiendo el concepto del técnico como sujeto de decisión y conducción global de la empresa. Al momento de asumir el técnico el poder de decisión con criterio de racionalidad económica, surge según Ochoa (1995), el fenómeno tecnocrático (lo que compartimos como concepto) caracterizado por dos elementos: el tecnócrata, con poder de decisión, formación para la dirección basada en la racionalidad económica y la organización tecnocrática dirigida por los tecnócratas.

En la gestión pública no hay precisión cronológica en cuanto a la aparición de la manifestación tecnocrática, pero aproximadamente después de la postguerra se constituye en un fenómeno político para los Estados y se explica entre otras cosas por la expansión económica de los países Industrializados. El fenómeno tecnocrático público ha sido objeto de un serio debate en cuanto a su origen, por lo tanto, es estudiado desde varias ópticas. Para nuestro análisis compartimos el concepto tecnocrático, que lo define como producto de la necesidad de aplicar los avances técnicos y científicos para dar respuestas a los fines políticos del capital y del Estado (Ochoa, 1995).
La exigencia de eficacia y eficiencia en el cumplimiento de las nuevas reglas del juego han conducido a prácticas de gestión diferentes, las cuales han modificado profundamente las relaciones del Estado con la sociedad por una parte y con los funcionarios por la otra....y el ascenso a éste, de técnicos, denominados tecnócratas, quienes conjuntamente con los empresarios son los sujetos responsables de impulsar la nueva política estatal por una parte y el nuevo modelo de gestión por la otra (Ochoa, 1999: 77).

Puntualizando que desde la dimensión política del Estado se definen los objetivos y se toman e imponen las decisiones para el colectivo y, de esa forma se consolidan a través de la racionalidad económica los intereses de las elites dirigentes y de los grupos económicamente poderosos, concretándose su ejecución en la dimensión operativa que es la gestión pública.

Ochoa (1995), señala que, el fenómeno tecnocrático es producto de la revolución técnico-científica, aunque en un proceso particular de intervención del Estado en la acumulación de capital y su legitimación. Se transforma el papel del Estado en su rol predominantemente económico para favorecer la acumulación privada del capital y su legitimación.

En el caso venezolano, la inserción al circuito capitalista se produce en el inicio del siglo XX con la aparición y explotación petrolera, asociándose los capitales de la burguesía internacional con los capitales nacionales tanto de las oligarquía terrateniente como de la comercial, garantizando el orden económico (acumulación de capital). Por otra parte, con el inci- 
piente Estado-Nacional impulsado en el gobierno del presidente Juan Vicente Gómez, se aseguró el orden interno político y social (legitimación).

El modelo tecnocrático presenta un esquema de acción que requiere profundizar el papel del Estado en el proceso de acumulación y subordinar a éste su función de legitimación, así como por medio de la racionalidad económica de los tecnócratas favorecer el crecimiento económico al cual se subordina el bienestar social.

Para implantar el modelo Tecnocrático se requiere de unos especialistas denominados tecnócratas que cumplen ciertos requisitos: ser expertos en materia de dirección y gerencia, determinar las decisiones en las organizaciones, atender los intereses de los propietarios, poseer una ideología capitalista que valoriza la ciencia y la técnica y por supuesto manipular según las recompensas, y amenazas. En consecuencia, el control ideológico es sutil, pero legitima a quienes detentan el poder; porque utilizan mecanismos como la persuasión, la manipulación, concesión de beneficios para amoldar el comportamiento de los individuos a lo esperado (Gamboa y Suárez, 1997).

Ahora el proceso tecnocrático según Ochoa (1995), funciona a través de tres mecanismos: 1) Favorece a la acumulación por medio de la expansión de capital privado y su rentabilidad con estrategias como inversión privada en los planes de expansión económica, privatización periférica con el traspaso de capital privado a actividades subsidiarias de empresas estatales, entre otras; 2) Logro de legitimación subordinada a la raciona- lidad económica y principalmente radica en mostrar los niveles de eficiencia alcanzados en las instituciones dirigidas, esto pasa por trasladar costos y conflictos a otras instancias públicas, reducir el numero de trabajadores, aplicación de técnicas de productividad, represión, meritocracia, otros; 3) Defensa de sus propios intereses, destacando para ello la reproducción ideológica y las relaciones estrechas con los sectores económicos.

Evidentemente al aplicar los criterios del proceso tecnocrático a la administración pública resaltan las incongruencias, básicamente porque se contradice con los principios sociales de equidad, justicia, igualdad de oportunidades y con la democracia propiamente dicha al obstaculizar las posibilidades de participación ciudadana, transparencia y eficiencia de la gestión pública.

Sin embargo, creemos desde nuestra percepción, necesario establecer ciertas diferencias relacionadas con la decisión y la implementación de la decisión política por parte de los técnicos. Existe una directriz política cónsona al proyecto o programa del gobierno desde donde se estructuran las decisiones y emanan a través de la gestión pública, con lo que se aclara que la gestión ejecuta decisiones estratégicas de primer orden que han sido diseñadas desde arriba, aunque por su puesto, reconocemos la capacidad de los funcionarios para decidir al momento de concretarlas en la sociedad, evidentemente el criterio aplicado no es el de la eficacia social, pero con algunas decisiones no hay margen de discrecionalidad para la concreción de las mismas por parte del funcionario o tecnócrata. Como diría Vilas (2001), la eficacia 
de la gestión se lleva a cabo con referencia a su marco político y a un plexo axiológico institucional ya determinado; la relación entre la gestión pública, la estructura socioeconómica y las orientaciones políticas del estado son de intima vinculación.

Asì mismo, asumimos y afirmamos que los técnicos son efectivamente necesarios para resolver problemas sobre los que hay tomar decisiones especializadas e implantarlas técnicamente, pero sin dejar en sus manos el poder exclusivo y discrecional absoluto, para ello debe intervenir el ciudadano junto a los órganos del Estado en las decisiones y la vigilancia de los resultados.

Para corregir algunas distorsiones de la gestión pública, se han propuesto reformas administrativas en Venezuela desde la década de 1980, con las cuales se comenzó a reconsiderar la gestión pública como instrumento válido para las transformaciones requeridas de frente al fracaso político y económico del sistema venezolano.

A partir de 1989, los cambios han sido significativos si se considera la elección de gobernadores y de alcaldes, así como la aprobación de leyes que darían impulso a la reforma del Estado, tales como: la Ley de Descentralización, Delimitación y Transferencia de Competencias del Poder Público, la reforma a la Ley Orgánica del Régimen Municipal, entre otras de trascendencia para el proceso de descentralización y del desarrollo local.

Paralelamente con la descentralización se intenta transformar el paradigma burocrático existente, y con la configuración del municipio como unidad polí- tica primaria autónoma, facilitar la inserción del ciudadano en la resolución de sus propios problemas. De tal manera, que se puede avanzar hacía un ejercicio público más solidario y participativo, eficiente como producto de su discrecionalidad y autonomía para tomar las decisiones consensuadas que puedan ejecutarse de forma más inmediata tanto en el espacio como en la temporalidad.

Sin embargo, aun cuando este es el propósito, el resultado actual no apunta hacia el reconocimiento de la autonomía política para los municipios, por el contrario, la realidad del proceso de descentralización ha tomado sólo el nivel Estadal como escenario. Según Córdova (1996), las razones por las cuales la descentralización se ha desarrollado hacía los estados son de carácter económico dado que en los municipios no se encuentran estructuras asociadas a la economía del mercado. Pero aunque compartimos lo anterior, también es necesario considerar el papel de los partidos políticos a nivel municipal, el cual no ha sido diferente a su práctica al del ámbito nacional y regional. Lo que se persigue en los tres niveles del Estado es resguardar sus intereses parcelarios y cuotas de poder, antes que compartir y ampliar la participación en la toma de decisiones con los ciudadanos y las comunidades, erigiéndose como representantes e intermediarios pero sin consultar las necesidades y requerimientos del colectivo, quedando aislados de su entorno y reproduciendo el modelo de relación Estado-Sociedad con el que han perdido credibilidad.

La administración pública venezolana en la actualidad continua siendo guiada por un esquema representativo, 
pero las grandes transformaciones políticas en repuesta a la crisis de la democracia representativa aunada a la creciente urgencia de los ciudadanos de involucrarse directamente en la toma de decisiones gubernamentales ha producido como respuesta el establecimiento de una normativa constitucional dirigida a ampliar y responsabilizar a los ciudadanos de la gestión pública en los diferentes niveles.

Tal como lo expresa el artìculo 62 en la Constitución de la República Bolivariana de Venezuela,

Todos los ciudadanos y ciudadanas tienen el derecho de participar libremente en los asuntos públicos, directamente o por medio de sus representantes elegidos o elegidas. La participación del pueblo en la formación, ejecución y control de la gestión pública es el medio necesario para lograr el protagonismo que garantice su completo desarrollo, tanto individual como colectivo (Asamblea Nacional Constituyente:1999).

Esto ha sido determinante en el contexto municipal, por considerarse que es el espacio de mayor posibilidad para la participación directa y protagónica de los ciudadanos entre otras cosas, por sus particularidades como: el numero de habitantes y sus relaciones de mayor cercanía; la posibilidad de juzgar resultados de gestión en cuanto a la calidad de las políticas públicas, y por la inmediatez de la evaluación; y la responsabilidad directa de los habitantes frente a la formulación y ejecución de las mismas.

Desde esta perspectiva, el contexto municipal es el espacio de concertación política más cercana a los ciudadanos y cuyas posibilidades de participación son concretas, vinculantes con el resto de la sociedad, con las relaciones de poder, adicionalmente le permite actuar como elemento de movilización solidaria requeridas para la participación, en definitiva para construir nuevas pautas de relación estado-sociedad, donde el ciudadano es el centro de dicha relación.

\subsection{Participación ciudadana}

Las realidades que enfrenta el ciudadano en las diversas áreas de su desenvolvimiento social abarcan tanto la búsqueda de mejores condiciones de vida, como del compromiso solidario con otros, en una mutua interrelación que sea de beneficio para todos. En esa dinámica gregaria se deberían basar las relaciones sociales, pero históricamente su correspondencia ha sido determinada por los aspectos económicos y políticos articulados a través del Estado en los diversos ámbitos: nacional, regional y local, abarcando tanto el espacio público como privado de los mismos.

En el debate contemporáneo sobre lo inherente al espacio público y lo que es para el espacio privado con respecto a la toma de decisiones, se define en términos de resolución de problemas, pero problemas que en la practicidad de las soluciones se plantean con diferentes enfoques porque prevalece la óptica de la gestión y con ella los intereses y racionalidad de cada uno, por lo tanto se cuestiona hasta que punto esa racionalidad mezclada haya contribuido también a la crisis del sistema político.

La reclusión de los ciudadanos hacía sus espacios privados y aquello que en la postmodernidad se ha definido como el desencanto con la política, pro- 
vocada por sus intermediarios y representantes o por ellos mismos desmotivados o desinteresados a involucrarse en las decisiones públicas, ha determinado la erosión de la potestad y eficacia del Estado para brindar soluciones a las mayorías, por lo menos de forma equitativa.

En consecuencia, la gestión pública en cualquier espacio incluyendo el municipal se ha visto afectada por la ejecución racional económica que le ha determinado, así como también la concepción de las expectativas ciudadanas. El municipio por ser el espacio comunitario por excelencia sufre de manera inmediata y directa los efectos de la ineficiencia pública. Sin embargo, lo anterior es determinante para algunos ciudadanos, pero las realidades evidencian un creciente interés de ciudadanos más informados, proactivos, contestatarios que aún desencantados de los políticos buscan su propias vías de participación en los asuntos públicos que afectan directamente su calidad de vida.

Las transformaciones sociales que se suceden en la actualidad han generado complejas crisis en el entorno político, afectando directamente al Estado y sus relaciones con la sociedad; al sistema democrático como forma de gobierno y a los mismos individuos en la valoración de su participación en los asuntos públicos.

Lo político encierra el conjunto de relaciones de poder que se entretejen en cualquier sociedad, grupo u organización, asunto determinante en las decisiones y capacidad de respuesta que se esperan surjan en la solución de problemas y / o necesidades. En el entorno contemporáneo las exigencias son mayores debido a lo complejo de las condiciones competitivas y desiguales presentes en cualquier ámbito incluido el de carácter público.

La participación ciudadana se acepta como un factor fundamental del análisis sociopolítico de una colectividad para definir el funcionamiento y el ejercicio del poder, de cómo El estado se ha relacionado con la sociedad y cómo los individuos particularmente se asocian a la dinámica del Estado. Desde lo público es donde los ciudadanos pueden superar sus espacios individuales en armonía con los intereses mayoritarios y formalizar el espectro jurídico donde se desenvuelva el Estado-Nación como entidad espacial e institucional que los agrupe.

La inclusión del ciudadano de forma directa en los asuntos públicos se determina según la forma de gobernar como del tipo de democracia, donde los canales de participación se suponen abiertos hacía los ciudadanos de manera inmediata, pluralista y deliberativa. Implica la intervención de los individuos en las actividades públicas, siempre y cuando sean portadores de intereses sociales y entendiéndola como un medio de socialización de la política que se supone abrirá nuevos espacios y mecanismos de articulación del Estado con sujetos sociales, interacción entre la comunidad y los diferentes niveles de gobierno en la búsqueda de soluciones a los problemas que afectan directamente al colectivo social $\mathrm{Cu}$ nill, 1991).

Para una sociedad organizada democráticamente se han concebido varias expresiones, entre ellas la relacionadas con la participación indirecta o directa de los ciudadanos en los asuntos públicos, derivándose las concepciones de Demo- 
cracia Representativa y Democracia Participativa. La distinción entre ambas tiene su origen en dos concepciones opuestas del ejercicio de la soberanía y el poder. La diferencia radica en que el ideal de democracia participativa posibilita el ejercicio directo del poder por el pueblo, mientras que el sistema de la democracia representativa, el poder es divisible o distribuible en un conjunto de instituciones o intermediarios que se controlan mutuamente para impedir la acumulación del poder en un único actor político, sea el Estado o sea el Pueblo (Panorama, Agosto 2004:8). Sin embargo, no compartimos este último aspecto sobre la representatividad y la distribución del poder entre los diversos actores sobre todo cuando lo comparamos con realidades de nuestro país, donde los partidos políticos se convirtieron en monopolizadores de los canales de participación y se transformaron en elites de poder fundadas en las relaciones clientelares, sectarias y estrictamente verticales en la toma de decisiones. Con el modelo representativo aplicado en Venezuela, el Estado se convirtió en un ente ajeno a las realidades del pueblo, sobredimensionado en sus funciones y con un esquema de representatividad condicionado por los arreglos de poder de las elites constituidas de espaldas a las demandas y necesidades de la sociedad civil. No obstante, creemos también que el esquema representativo no es un mal sistema por si mismo, por el contrario una participación eficiente exige ciertos grados de intermediación para facilitar la toma de decisiones, pero los actores a intervenir como representantes deben necesariamente incluir ciudadanos electos por las comunidades. En este aspecto coincidimos con Cunill (1991) al considerar que la participación ciudadana no es sustituta de la democracia representativa, bien podría considerarse como un complemento a la misma, basada en nuevas condiciones que requieren el perfeccionamiento institucional de los sistemas de representación política y social, orientado a incrementar la incidencia de representación en los sistemas de toma de decisiones y la responsabilidad de los actores.

En síntesis, se requiere un nuevo Estado con una renovada administración donde se amplíen los controles ciudadanos y se democratice la gestión pública en todos los niveles: nacional, regional y local. La democratización profunda exige por una parte una mayor e indispensable eficiencia en la gestión del Estado, y por otra parte, una vigorosa presencia de los ciudadanos organizados.

El ejercicio del poder supone que el ámbito político-público sea el artífice de la vida colectiva, por lo cual los intereses de los ciudadanos deben coincidir con los intereses de la sociedad. En esta relación Estado-Sociedad la conciencia social es proporcional a la eficacia del Estado, es decir cuanto mayor conciencia y participación ciudadana se expresen en la sociedad, mayor debe ser la capacidad del Estado para gestionar pertinentemente los asuntos públicos y mayor es la pluralidad, diversidad y organización de la sociedad como tal. Aunado al hecho generalizado hoy día, de la fuerte presión que están ejerciendo los ciudadanos para ser partícipes de las decisiones públicas que afectan su calidad de vida, además de ser una ciudadanía que dispone de mayores cuotas de información y conocimiento, 
sobrepasando los mecanismos clásicos de intermediación política donde los representantes ya no interpretan los intereses de la sociedad.

La participación no se mide en términos absolutos sino en grados o niveles, teóricamente podemos pensar en problemas sociales manejados dentro de un continuo que va desde el tratamiento exclusivo por parte del gobierno, hasta el otro extremo donde la exclusividad sea de la sociedad. El enfoque de la gestión participativa debería insistir en la participación de la sociedad pero con el apoyo del gobierno y los recursos que administra. El Estado se soporta financieramente de los recursos que provienen de su misma sociedad, derivando una obligación legal y ética de los funcionarios públicos en el manejo de los recursos y en la rendición de cuenta sobre los mismos, además de garantizar el cumplimiento de las decisiones ciudadanas y gestionándolas con eficiencia.

Compartimos el criterio de que el carácter técnico de las decisiones y el empleo de indicadores de gestión como eficiencia y eficacia no es incompatible con la gestión pública, por el contrario proponemos que para lograr los objetivos es necesario establecer criterios cuantitativos para priorizar las necesidades, sólo que deben ser asociados con otros indicadores como equidad, oportunidad, cobertura, entre otros; incorporando el criterio de eficacia con servicio social.

La participación distingue dos modalidades básicas de acción: la participación directa que se ejerce de forma individual y colectiva, y la indirecta donde organismos intermediarios actúan como representantes de determinados intereses, así lo han hecho los partidos políticos y en la actualidad órganos de competencia ciudadana como las asociaciones de vecinos y más técnicamente los consejos locales de planificación pública (previstos constitucionalmente), los cuales actúan como organismos intermediarios entre ciudadanos y municipios.

En los países de América Latina se están intentando nuevos mecanismos de articulación, sobre todo en el ámbito de los municipios, instancia institucional generalmente responsable de la implementación de políticas sociales. Requiriendo formas de asociación con la sociedad para encontrar soluciones al problema de la desigualdad social y simultáneamente la búsqueda de justicia y eficiencia del gobierno.

La participación es de gran trascendencia como fenómeno socio-políti$\mathrm{co}, \mathrm{y}$ a nosotros nos interesa resaltar sus mecanismos y procedimientos para intervenir en la administración pública en la toma de decisiones colectivas a nivel municipal, Para ello analizamos desde las innovaciones que desde el marco constitucional venezolano se han planteado, a partir de 1999.

La Participación Ciudadana implica un amplio proceso de reestructuración de la gestión pública como organización del Estado, pero también incluye un cambio de paradigmas culturales en el ideario colectivo para involucrarse directamente en las actividades públicas. A manera de: articular el proceso administrativo con estructuras flexibles, transparentes y oportunas; y gestionar la toma de decisiones mancomunadas. "Los miembros de una organización independientemente del nivel en que se encuentran, toman decisio- 
nes de impacto a corto y a largo plazo, requiriendo información precisa, pertinente y oportuna acerca de la organización, como base para la toma de decisiones" (Ferrer y Gamboa, 2001:53), en consecuencia debe habilitar amplios canales para facilitar la participación de modo que la discusión y toma de decisiones sean concertadas, conciliadas y en función de las verdaderas prioridades colectivas. Incluye las capacidades técnicas que son necesarias para alcanzar la eficacia y eficiencia de las instituciones, que continúan siendo indicadores importantes para el desempeño, y por otro lado la racionalidad del ciudadano debe incluir sus propias necesidades para una mejor calidad de vida pero considerando las expectativas de sus conciudadanos en forma ética, equitativa y solidaria. Por lo tanto debe plantearse un cambio de valores tanto humano como organizacional.

Kliksberg (1989, 1997a, 1997b), considera que resultan imprescindibles nuevos modelos organizacionales, no convencionales, de carácter descentralizado, con alta flexibilidad, con capacidad de participación social, negociación, concertación. Y a su vez señala, que la gerencia social ha avanzado en varias direcciones incluidas la potenciación de la descentralización, modelos participativos, diseño de meta-redes y control social. Coincidiendo con Cunill (1997) al referirse a un posible fortalecimiento institucional del gobierno al introducir eficiencia y eficacia a la racionalidad gubernamental junto con valores políticos referidos a la transparencia y la responsabilidad social.

De tal manera, que el propio Estado pueda asumir los retos de una reforma institucional con nuevos modelos organizacionales donde la eficacia, como ya lo hemos expresado, no sean sólo aspectos de la racionalidad económica, sino criterios compartidos con la ciudadanía para la transformación de la gestión pública.

\subsection{Los consejos locales de planificación local}

En Venezuela con la Constitución de 1999, se conserva la definición del municipio como unidad política primaria de la organización nacional con personalidad jurídica y autonomía para elección de sus autoridades, gestión de las materias de su competencia y creación, recaudación e inversión de sus ingresos. Lo novedoso es la incorporación de la participación ciudadana al proceso de definición, es decir toma de decisiones participativa y ejecución de la gestión pública en forma efectiva, suficiente y oportuna.

El marco legal se ha orientado con la Constitución Nacional hacía el redimensionamiento de la participación ciudadana, con la renovación institucional se plantea la creación del Consejo Local de Planificación Pública (CLPP), presidido por el Alcalde o la Alcaldesa e integrado por los concejales y concejalas, los presidentes y presidentas de las juntas parroquiales y representantes de las organizaciones vecinales y otros de la sociedad organizada, de conformidad con las disposiciones que establezca la ley (Asamblea Nacional ConstituyenteCRBV, 1999. Art.168). Los CLPP expresan la soberanía popular que se fundamenta en el ejercicio del derecho a participar en el contexto del gobierno municipal. 
El Consejo Local de Planificación, es la instancia encargada de promover la participación organizada de la población en los procesos de planificación participativa a ser desarrollados a nivel del municipio. Su propósito fundamental es lograr la integración de las comunidades organizadas y grupos vecinales, promover la organización social mediante el establecimiento de Consejos Parroquiales y Comunales que garanticen la participación ciudadana. Se encarga del proceso de formulación, seguimiento, control y evaluación de los planes de desarrollo municipales. Entre sus funciones se expresan: Recopilar, procesar y priorizar las propuestas de las comunidades organizadas, presentar propuestas dirigidas hacía la atención de necesidades y capacidades de la población, controlar y vigilar la ejecución del Plan Municipal de Desarrollo, proponer al gobierno nacional, estadal o municipal las medidas de carácter jurídico, administrativo o financiero, necesarias para el cumplimiento de funciones y consecución de los objetivos del municipio, elaborar el mapa de necesidades del municipio, evaluar la ejecución de los planes y/o proyectos a realizar en las parroquias y comunidades (Ley de Consejos Locales, 2002).

La organización de los CLPP debe abocarse a la consecución de los objetivos y funciones para los que fue creado, para lo cual debe: definir los niveles de autoridad; distribuir los recursos humanos, técnicos y financieros requeridos para su estructuración; diseñar la organización con criterios de flexibilidad de acuerdo al municipio; constituirse en el órgano máximo de decisión; definir el rol trascendental y la membresía otorgadas a los ciudadanos elegidos para tal ejercicio; creación de comisiones permanentes por las áreas económicas, Social, Política, Territorial e Internacional y toda la estructura requerida para gestionar los asuntos públicos. La aspiración con los Consejos es fundar un binomio de acción para la gestión pública de ciudadanos y gobiernos, que deberán generar entre muchas cosas: el plan de desarrollo concertado municipal, mecanismos de concentración, información confiable y oportuna sobre los planes, propuestas, programas y proyectos, asesoría técnica, plan operativo, memoria y cuenta.

Adicionalmente, se propone el ejercicio de Democracia Participativa a través de figuras jurídicas e institucionales para hacer del pueblo el depositario del poder. Algunas de estas formas de participación se expresan en los referendos, las asambleas de ciudadanos, los Consejos Comunales, entre otros.

Por su parte los Consejos Comunales, representan desde el punto de vista normativo, la innovación más acorde para la Democracia Participativa. En el marco Ley de los Consejos Comunales se contempla, como instancia de participación, articulación e integración de las organizaciones comunitarias, que permite el ejercicio directo de la gestión de las políticas públicas por parte de los ciudadanos, para responder a sus necesidades y aspirar a una sociedad justa y equitativa.

En síntesis confiamos en que sea a través de estos mecanismos de inclusión de los ciudadanos a los asuntos públicos para alcanzar una gestión con eficacia y eficiente; pero con compromiso social, amplia, transparente, responsable, justa, solidaria, equitativa; y con responsabili- 
dades compartidas del gobierno, los funcionarios y los ciudadanos.

\section{Conclusiones}

La toma de decisiones pública es afectada por el proceso tecnocrático como modelo administrativo frente a la posibilidad de la participación de los ciudadanos en la gestión, la racionalidad económica se superpone a las necesidades sociales.

La gestión venezolana se concebida desde la mentalidad industrial y de las elites de poder produciendo una alineación burocrática cuya racionalidad favorece los intereses de sectores privilegiados y determina la imposición de ciertos criterios. Criterios como el del control jerárquico, por mencionar uno, el cual no concede independencia ni libertad a los individuos en la toma de decisiones tan necesarias si se quieren establecer criterios participativos acordes con la gestión social, en función del bienestar de toda la ciudadanía y comunidad en la cual ellos mismos formulen sus problemas y planteen las posibles soluciones.

El carácter técnico de las decisiones y la apreciación de indicadores de gestión como eficacia, eficiencia y la transparencia no son contraproducentes; por el contrario pueden mejorar la capacidad de gestión pública, mejorar la democracia, ampliar la capacidad de buen gobierno; porque la calidad de gestión pública puede ser medida con indicadores como eficiencia, eficacia, responsabilidad y otros, pero con la condición de priorizar el compromiso social del Estado, a través de: equidad, transparencia, responsabilidad, cobertura y pluralidad.
La gestión pública sin la participación de los ciudadanos continuaría perdiendo credibilidad, legitimidad y eficiencia, pero también es cierto que los ciudadanos sin la estructura y recursos de la administración y del gobierno se negaría la posibilidad de concretar resultados, por lo tanto se debe dirigir la atención hacía una gestión mancomunada en un binomio Estado-Ciudadano. Además el impulso del creciente interés de los ciudadanos por participar para mejorar su calidad erosiona aún más la legitimidad de los estados y de los gobiernos.

No obstante reconocemos que el proceso de Participación presenta ciertos escollos a superar entre los que podríamos mencionar: la cultura clientelar de la sociedad venezolana enraizada con el modelo populista de los últimos decenios, el desconocimiento de ciertos valores estratégicos para la participación como; el compromiso social, el trabajo solidario y la eficacia social, la falta de interés de algunos ciudadanos para participar, la exclusión del sistema político de los ciudadanos en situación de pobreza extrema por tener prioridades de subsistencia, la resistencia de los gobiernos y funcionarios en facilitar los canales de participación hacía los ciudadanos y las misma rigidez de las estructuras jurídicas que no ejecutan con celeridad los procesos y procedimientos legales necesarios para concretar la Participación Ciudadana.

Hoy día en Venezuela coexisten dos modelos de gestión pública, por una parte el modelo tecnocrático que perdura en las estructuras organizativas de los municipios, y por otra, se expone idealmente un modelo participativo que debe- 
ría implantarse definitivamente en toda la administración pública. Para concretar la intervención del ciudadano en los asuntos públicos contenida en la normativa constitucional venezolana debería impulsarse enérgicamente desde el contexto municipal, es allí donde nosotros interpretamos se propone un modelo más directo, efectivo, inmediato, democrático de relación Estado- Sociedad.

Consideramos de sumo cuidado que la participación ciudadana no debe ser iniciativa ni impulsada por los sectores del gobierno, su papel se concentra en brindar a los ciudadanos el soporte mancomunado, legal, administrativo y económico para su viabilidad. Tampoco desde los sectores económicos vistas ya todas las consecuencias negativas generadas en la penetración de este sector en la toma de decisiones públicas, lo cual no limita su participación pero dentro del contexto de la sociedad civil y como ciudadanos en igualdad de condiciones frente a los otros ciudadanos.

Los ciudadanos deben asumir el compromiso de la participación con el objeto de mejorar su espacio de vida pero considerando las necesidades de sus conciudadanos creando redes de solidaridad y compromiso social para la consecución de los fines colectivos y colaborando en una nueva gestión pública donde los funcionarios sean administradores en la consecución de esos fines. De esa forma articular la relación del Estado con la Sociedad pero desde la perspectiva ciudadana.

La participación ciudadana es un requisito para la verdadera evolución democrática, caracterizada por un ciudada- no responsable, proactivo, solidario, capaz de mejorar sus realidades socioeconómicas, junto a un cuerpo de representantes que faciliten la articulación y expresión popular de la toma de decisiones públicas, así como un Estado garante de los mecanismos y recursos necesarios para el desarrollo participativo.

\section{Referencias Bibliográficas}

Asamblea Nacional Constituyente (1999). Constitución de la República Bolivariana de Venezuela, Gaceta oficial $N^{\circ}$ 5.453 Extraordinario. Caracas, Venezuela.

Asamblea Nacional Constituyente (2002). Ley de Consejos Estadales de Planificación y Coordinación de Políticas Públicas. Gaceta oficial. Caracas, Venezuela.

Asamblea Nacional Constituyente (2006). Ley de los Consejos Comunales. Gaceta oficial. Caracas Venezuela.

Broitman, Lily (2004). Políticas públicas y control de la de la gestión pública. Los retos de la Administración Pública. Módulo: Diplomado Ciudadanía, Control Democrático de la gestión pública y Participación Ciudadana. UNICA. Maracaibo.

Córdoba Jaimes, Edgar (1996). La reforma Administrativa en Venezuela y Colombia. Revista Venezolana de Gerencia Vol. 1, N² 2, Diciembre. Universidad del Zulia, Maracaibo, Venezuela.

Córdoba Jaimes, Edgar (2000). La flexibilización Laboral en los entes descentralizados de competencia exclusiva. Revista Venezolana de Ciencias Sociales Vol. 4, $N^{\circ} 2$, Diciembre. Universidad Nacional Experimental Rafael María Baralt. 129-145. Cabimas, Venezuela. 
Coriat, Benjamín (1982). El taller y el cronómetro ensayo sobre el taylorismo, el fordismo y la producción en masa. España. Siglo veintiuno editores.

Cunill, Nuria (1991). Participación Ciudadana. Dilemas y Perspectivas para la democratización de los Estados latinoamericanos. Venezuela. CLAD.

Cunill, Nuria (1997). Repensando lo público a través de la sociedad. Nuevas formas de gestión pública y representación social. Venezuela. Nueva Sociedad. CLAD.

Gamboa Cáceres, Teresa y Suárez Picón, Cira (1997). Control y evaluación: funciones clave del poder económico. Revista Venezolana de Ciencias Sociales Vol. 1, No 1, Julio. Universidad Nacional Experimental Rafael María Baralt. pp. 53-76. Cabimas, Venezuela.

Ferrer, María A. y Gamboa C, Teresa (2001). Control de gestión y desarrollo de indicadores financieros y no financieros. Revista Venezolana de Ciencias sociales Vol. 5, $\mathrm{N}^{\circ} 1$, Junio. Universidad Nacional Experimental Rafael María Baralt. pp. 52-71. Cabimas, Venezuela.

Kaplan, Marcos (1997). Crisis y Reformas del Estado Latinoamericano. Revista del CLAD Reforma y Democracia. № 9. Caracas.

Kliksberg, Bernardo (1989). ¿Cómo formar Gerentes Sociales? elementos para el diseño de estrategias. En: B Kliksberg (comp.) ¿Cómo enfrentar la pobreza? Agustina. Grupo Editor Latinoamericano.
Kliksberg, Bernardo (1997 a), Pobreza. Un tema impostergable. FCE. PNUD. México.

Kliksberg, Bernardo (1997 b). Hacia una gerencia social eficiente. Algunas cuestiones clave. "Il Congreso Interamericano del CLAD sobre la reforma del Estado y de la Administración pública". Isla de Margarita, Venezuela.

Ochoa H., Haydeé C. (1995). Tecnocracia y empresas públicas en Venezuela (1948-19921). Venezuela. La Universidad del Zulia.

Ochoa H., Haydeé C. (1999). Elementos teóricos para el estudio de la modernización administrativa de las gobernaciones en Venezuela. Revista Venezolana de Ciencias Sociales. Vol. $3 \mathrm{~N}^{\circ}$ 1. Junio. Universidad Nacional Experimental Rafael María Baralt. pp. 7091. Cabimas, Venezuela.

Panorama (Agosto 2004). Metamorfosis de la Democracia: ahora el mando es del pueblo soberano. Venezuela. Voces Jurídicas.

Pastor, Manuel (1999) coord. Fundamentos de Ciencia Política. Mc Graw Hill Interamericana de España.

Vallespìn, Fernando (2000). El futuro de la Política. Grupo Santillana de Ediciones, S.A.

Vilas, Carlos M. (2001). El síndrome de Pantaleón. Política y administración en la reforma del Estado y la gestión de gobierno. Revista de Ciencias Sociales. Vol. VII. $\mathrm{N}^{\circ}$ 2. Mayo-Agosto. Universidad del Zulia. pp. 173-198. Maracaibo, Venezuela. 